\title{
Narratives on the Creation of an Educational Museum of Science and Consciousness in a Public School: (Re)Thinking Spaces and Creating Environments for Scientific Literacy
}

\author{
Guy Barros Barcellos \\ Programa de Pós-GraduaçãoemEducaçãoemCiências e Matemática-PUCRS, Porto Alegre (RS), Brazil; \\ Basic Education Direction of Aelbra, Canoas (RS), Brazil \\ Ricardo Wilian Da Costa Assumpção \\ Colégio ULBRA São Mateus, Cachoeirinha (RS), Brazil \\ Diego Lippert \\ Colégio ULBRA São Lucas, Sapucaia do Sul (RS), Brazil \\ Zulma Elizabete De Freitas Madruga \\ Programa de Pós-GraduaçãoemEducaçãoemCiências e Matemática-PUCRS, Porto Alegre (RS), Brazil
}

\begin{abstract}
This article aims to analyze the relevance of pedagogical actions that break with the norms of educational institution and rethink the school environment through the implementation of an "Educational Museum" in a public school, located in a vulnerable region in the municipality of Porto Alegre (RS). This is a qualitative research, in which the authors use narratives as a method of data collection and analysis. As a result, it was observed that the pedagogical approach of remodeling an educational space allowed students to become protagonists of their own learning, in turn promoting scientific literacy (SL).
\end{abstract}

Keywords: scientific literacy (SL), narrative inquiry, science teaching environments

\section{Introduction}

Developing scientific literacy (SL) is a contemporary challenge, once it requires a rupture from the logocentric logic and the unravelling of the still very common "banking education" (Freire, 2011a). Promoting SL does not mean using mechanical learning or making someone comprehend a set of previously selected knowledges? It is a deep and complex process. It requires, therefore, intellectual sedimentation, ethical and aesthetic reflections.

Chassot (2003) stated that SL does not mean dominating a list of subjects, but having enough knowledge to comprehend and act within the reality a person lives. Thus, we can weave a bridge to Edgar Morin's

Guy Barros Barcellos, M.Sc. in Science and Math Education, Ph.D. candidate in Science and Math Education (Programa de Pós-Graduação em Educação em Ciências e Matemática da Pontifícia Universidade do Rio Grande do Sul-PUCRS) and Pedagogical Coordinator of Basic Education Direction of Aelbra (Lutheran Educational Association of Brazil).

Ricardo Willian Da Costa Assumpção, high school student of Colégio ULBRA São Mateus (Lutheran University of Brazil).

Diego Lippert, mathematician and high school teacher of Colégio ULBRA São Lucas (Lutheran University of Brazil).

Zulma Elizabete De FreitasMadruga, Ph.D. in Science and Math Education (Programa de Pós-Graduacão em Educacão em Ciências e Matemática da PontifíciaUniversidade do Rio Grande do Sul-PUCRS). 
thoughts (2004), and consequently, to those of Michel de Montaigne (1980) when he states it is better to have a "well-made head" than a "well-filled head," meaning an intelligence capable of understanding the complexity, and subsequently, the depth and reach, of the world where he or she lives or desires to live in. A mechanical ${ }^{1}$ and content-driven learning process might (apparently) be useful for student admission's tests and other institutional evaluations to which students are submitted. However, it is possible that the learning resulting from such activities is not plentiful enough for one to deal ethically with the emerging demands of life. According to Falcão (2009), teaching is much more than promoting the permanent etching of concepts, it is giving esteem to learning situations that allow the student to build their own cognitive baggage.

Therefore, changing the practice by which we teach Sciences requires modifications in the spaces used for scientific learning. These spaces cannot be "barren," poor in stimuli and possibilities. They cannot block creativity or distance students from the real world. Reality, in the perspective of SL, is a space for theorizing, where we see contents and subjects "emerge" that aid us in building knowledge and creations. The practical learning of scientific knowledge to understand realities might occur when the person is affected by questions about the world, and starts trying to find answers. In that way, the act of understanding and explaining reality precedes the effort to learn subjects per se. Meaning, the contents "come to light" in the course of the elaboration of conceptualizations, developing thought in the attempt of establishing explanations of complexity.

Upon observing the "classroom" is still the school space where most teaching activities happen, intentionality becomes necessary on the part of the teachers, aiming to rethink that space, making it into a learning environment ${ }^{2}$. Thereby, our research is made up of narratives on the didactic work of a state public school teacher: the creation of a "Educational Museum of Sciences and Consciousness," in a public school located in a vulnerable area of Porto Alegre-RS.

This research is split into five distinct sections. The first one, titled "For a De(con)struction of Logocentric Science Teaching" broaches different aspects of science teaching in basic education, as well as its goals and challenges nowadays. We expose their criticism of Logocentrism, which does not support the demands of an Education that aims for the Political Empowerment of students (Lorenzon et al., 2015b), leading to airing solutions, such as the rejection of "bank education" and the praxis of a form of Science Teaching that encompasses SL.

In the second section, called "Spaces or Environments? Transfigurations" we present a "necessary" modification of school environments so they will be able to "catalyze" SL, once the aesthetic characteristics of a pedagogical system reveal certain epistemological conceptions implied in praxis.

In the third section, Methodology-"Narrative Complex: (Macro/Micro) Analysis," we describe a characterization of the methodological approach of the research is presented, as well as the means- theoretical and physical—used to collect and interpret data.

In the fourth section, titled Results and Discussion- "Explanatory Undulations: Dialogues of Complexity", wepresent the course of the (i)material and (psycho)logical "Genesis" of this space, both critically and analytically, tracing parallels between the narratives of the professor and of the authors with the theoretical structure previously presented. We present details of the tensioning of theories with significant elements to the narrative landscape. An analysis, which always fragments and splits, has its parts reunited in the last section.

\footnotetext{
1 Term used by David Ausubel in The Psychology of Meaningful Verbal Learning (1963).

2 In this research, we differentiate a "space of learning" from an "environment of learning." According to Horn (2004), the space is the physical disposition of materials in a place. It is an objective activity. The transformation of a space into an environment requires interpersonal relationships to happen in it that will transform and express feeling.
} 
The study concludes - converging and merging theory, method, practice, and data - in the section named Conclusions: "Synthesis and Considerations." In it, we weave ideas and reflections - within the universe of this research-about the possibilities of a school space. How the space-environment stimulates SL, once transfigured into an environment for the students, with the students and by the students. Beyond that, we explore how it may also allow a pedagogical freedom where the teacher and the students (re)signify knowledge in a contramundi movement, therefore disrupting with some dogmas of pedagogical common sense through actions that artifacts and mindfacts ${ }^{3}$ into museum pieces.

\section{For a De(con)struction of Logocentric Science Teaching}

The dominant perspective of the school curriculum has commonly been grounded in a logocentric approach, in which the teacher is considered a "transmitter of truths," contained in didactic books, to the students, who are mere receptors. In this perspective, knowledge is conceived as something ready-made and accessible through training activities, instruction and lecture classes. Even if, pedagogically and epistemologically questioned, this method is still common in many schools. It creates hierarchy, turning the teacher into the "vessel" of a "scientific" culture, and the students are seen as ignorant, who will absorb silently and passively, whatever is imprinted onto them by the words of the master.

In this view, the quality of the teachings would be ensured by its capacity to "transmit" and in the ability of "concentration" and "devotion" of the "listener student".

This approach reveals a conception in which learning is a direct and exclusive consequence of teaching. The student, by attending technical and professorial classes, would be able to fill their minds with these contents and get rid of the — so understood — popular knowledge: the wrong, the invalid, the spurious. Naturally, such advances would happen once the student took on a passive position before the lectures and exercises they would later receive, always conducted by the teacher. In this line of technicist approach, the student would develop a "memory-based" intelligence (Coll et al., 2000), where they could store a set of subjects previously selected, without giving thought to whether they see meaning in their learning. Learning Science in a critical understanding would then consist of an ethical obligation of the school curriculum.

However, certain pedagogical and psychological theories show that learning does not have a direct relationship with teaching. Therefore, we cannot expect the individual to learn what the teacher wants to teach, once that set of transmitted knowledge will be absorbed by a pre-existing structure of the student (Giordan \& De Vecchi, 1996). Teaching in an explanatory lecture $e^{4}$ fashion or with special strategies ${ }^{5}$ does not guarantee the student will learn exactly what the teacher desires. According to Moraes (2003),

[...] the knowledge a person acquires is not simply about internalizing the environment, nor is it only the result of the development of the individual's innate talents. Knowledge is built by what one learns through the interaction with the environment, in a process of constant assimilation, adjustment and balance. (p. 109)

In this constructivist approach of science teaching, bank education (Freire, 2011), in which not only would knowledge be transmitted, but certain cultural assumptions would be legitimized, should be replaced by an education based on the individual's activity. An education in which students would be motivated and stimulated

\footnotetext{
${ }^{3}$ Term utilized by Chassot in the book From Discipline to Indiscipline (2016).

${ }^{4}$ Meaning: slowly, giving examples, developing concepts and phenomena, seeking clarity, introducing the content in several ways, and showing images and objects.

5 With dynamics, mnemonic tricks, using music or comedy as resources.
} 
by their own interests, not by the mandatory character of attending class.

We understand by "constructivism" an educational tendency which involves a contrary position to a transmittable form of teaching, where the student, instead of copying, reciting and accepting ready-made knowledge, will operate, create, build knowledge based in the realities that surround them (Becker, 1992). Besides that, this perspective is named by Harres et al. $(2001$; 2012) as complex constructivism-which opposes a simplified constructivism that values the ideas of students as a result of their interaction with the environment, but sees them as mistakes, and therefore, as something to be replaced by unequivocal scientific knowledge. In that way, a mistake from the student is not seen as something to be corrected, or eliminated, but given certain value in the reality it exists in, "its own epistemic value" (Harres et al., 2001, p. 62).

In that sense, Freire (2011a) emphasized that,

The mechanicals memorization of the object's type is not true learning of the object or its contents. In that case, the apprentice works much more as a patient of transference of the object or of a subject than a critical, epistemologically curious subject, who builds knowledge of the object or is part of its creation. (p. 67)

Thus, being the patient of content transference does not mean learning significantly. Chassot (2003, p. 31) pointed out that "the greatest responsibility in teaching science is aiming for students to be transformed, by what we teach, into more critical-thinking men and women." Add to that, that the individual's ability for critical thought is not achieved through "bank education," once "teaching is not a purely mechanical transfer of the content, from the teacher to the student, passive and docile" (Freire, 2011b, p. 97). Teaching in a content-driven ${ }^{6}$ perspective would be to pacify the student to learn a culture conceived as certain and, in a certain way, dogmatic. Distancing ourselves from the epistemologies proposed by authors, such as Popper (1985) and Feyerabend (2011).

However, educating to form individuals of critical thinking does not presuppose creating a school that does not teach subjects, but a school that enables learning "[...] with knowledge, that is, to turn it into an instrument to ease a more adequate reading of the world and, especially, more critical" (Chassot, 2003, p. 93).

An education that leads the student to critical reflection about the world demands going beyond absorbing knowledge, and seeking for its meaning (Demo, 2010). For that author, the rebuilding of the meaning of knowledge only happens when knowledge is worked through argumentation and with an investment of originality. To form a critical individual, we require activity versus knowledge, always anchored in the reality in which the individuals are immersed. Therefore, it is relevant to operate under the paradigm of research on how to act critical and creatively about reality, where the individual seeks to ponder and react to problems, because, for Demo (2006, p. 12), "researching with the sole purpose of knowing would already be an alienating idea, reducing knowledge to a mere systematization of ideas."

Teaching Sciences without concern for creating SL may incur in a dogmatic education, which supports "one" scientific truth. The student is "made passive" before scientific culture, assuming, consequently, the existence of two distinct cultures. The first would be a scientific culture, "precise and exact," resulting from an abstraction of absolute truth. The second would be the culture of the students, coming from their empirical daily life and implied in their way of acting, where education should act in order to remove the students from the conditions of that culture. Having that in mind, we can state that teaching Sciences with SL seeks the political Empowerment of the students, meaning, "Allowing the individual the understanding of the complexity

${ }^{6}$ We assume, in this article, that such pedagogical views disagree with the theoretical structure of SL praxis. 
of the reality in which they are inserted" (Lorenzon et al., 2015b, p. 42). By means of several expedients, and with a "concern for transforming reality in an object of analysis, criticism and understanding, hence, making the action of the individual vulnerable to the world they are a part of and rebuilding it according to their convictions" (Lorenzon et al., 2015, p. 43).

People have implicit theories they carry with themselves (Moraes, 2003b). These theories form the way in which people comprehend reality. For Moraes, this form of knowing differs from scientific culture, once implicit knowledge is practical knowledge, and scientific knowledge would be a way of understanding reality. However, this web of implicit knowledge individuals carry with them is their peculiar way of interpreting the world. It is, therefore, an ethical attitude from the teacher to respect this cultural legacy, without discriminating it for its experiential origin and the distinct level of abstraction it involves.

Furthermore, bank education is based on transfer of knowledge and might make students assume it is something that can be found, discovered, which is inconsistent with their own conception of science. Authors, such as Kuhn (2005) and Popper (1985), despite having opinions marked by differences, speak of the changeability of scientific thought, presenting science as a construction, rather than a "transcendental" discovery. Chassot (2003, p. 99) emphasized that "we must recue the drafts" of sciences, not present them as something ready and finished. For Ramos (2000), the school fails in thinking science epistemologically, because the sciences, as process and as product, are extremely rich. However, school education often trivializes the means of acquiring knowledge, as well as the knowledge itself that was selected for teaching. The first because science teaching is rarely explored as reference of process as far as the investigation, aiming to make the students see the characteristics and methods of scientific research. Where knowledge is concerned, in general, it is often cut up, fragmented, put out of context, as much in the real world as in its own process of constitution through Science and history (p. 31).

The image of science "found" in didactic books, able of being "transmitted" is of an empirical science, originating from a positivist culture. It is a science based on abstraction and detachment from reality, as if reality and tangible experiences were obstacles or could influence negatively in the construction of the student's knowledge. Cachapuz et al. (2005, p. 49) also pointed out that "transmitting already developed knowledge, very often leads to ignoring what were the problems that they intended to solve [...], not taking into account the limitations of current scientific knowledge or open perspectives". Therefore, an education aims to transmit knowledge (supposedly) ready for consumption, without bothering to allow students to understand the way in which it was produced. As a result, science is presented in a logocentric approach "as rhetoric of conclusions" (Cachapuz et al., 2005, p. 80). In addition, "One of the main goals, if not the main one, of science teaching is to allow the student to get a proper view of the nature of science" (Harres, 2003, p. 37).

Morin (2010, p. 24) made a counterpoint, emphasizing that "science is not only the accumulation of true truths," that is, science is not a juxtaposition of truths. This perception of science as something fallible and its historical accomplishments are not usually presented in everyday school life. Even if the "scientific accomplishment" is not the main objective of teaching Science (Cachapuz et al., 2005), understanding the processes by which science is produced is one of the dimensions of SL.

At this point, it is appropriate to clarify that the term "SL" is used in this manuscript, according to Sasseron and Carvalho (2011), 
[...] the term "SL" describe the ideas we have in mind and aim to realize when planning a way of teaching that will allow students to interact with a new culture, with a new way of seeing the world and its events, it can change them [...] through conscious practice enable by its interaction surrounded by scientific concepts and knowledge and skills associated with scientific realization. (p. 61)

Subsequently, being scientifically literate requires knowing the applicability of scientific knowledge for understanding nature and ethical and emancipatory action on situations and experiences that occur in a person's life (Chassot, 2003). However, the student must understand that the scientific knowledge production processes, seeing it as a rational constructive, methodical, subjective, and originating from deductive perspectives (Moraes, 2003b).

In this respect, being scientifically literate does not require a pragmatic and utilitarian view of science, but rather using it daily as a background to understand reality. It is looking at reality through science, understanding it and acting on it in order to transform it for the better (Chassot , 2003), integrating people around you and seeking the understanding of collective and individual freedom, respecting natural, cultural and social diversity.

It should also be noted that a praxis that aims for SL should consider the three "Structuring Axis of Scientific Literacy," once they "are able to provide necessary and sufficient bases to be considered at the time of preparation and planning lessons and proposals classes that aim for SL" (Sasseron \& Carvalho, 2011, p. 76). These are: (1) Basic understanding of terms, knowledge and fundamental scientific concepts; (2) Understanding the nature of science and the ethical and political factors surrounding its practice; and (3) Understanding the relationship between science, technology, society, and environment.

The three centerlines presented are facing educational aspects, in a theoretical dimension that will serve as the basis for the teaching action. In order to add to the characterization of SL, it is relevant to consider what the official documents of PISA ${ }^{7}$ exam advocate. To the Organization for Economic Cooperation and Development (OECD), $\mathrm{SL}^{8}$ is an individual's ability to engage with issues concerning science and the nature of science, being a reflective individual and a conscious citizen. A scientifically literate person is one that is prepared to participate in dialogues and actions based on scientific and technological knowledge (2013). This person, according to PISA, is entitled to:

1. Explain phenomena scientifically: Recognize, evaluate and explain natural and technological phenomena;

2. Assess and plan scientific research: Describe and evaluate scientific research and propose ways to address issues scientifically;

3. Interpret data and evidence scientifically: Analyze and evaluate the data, statements and arguments, taking appropriate scientific conclusions (OECD, 2013, p. 7).

In this perspective, the required skills for the SL are presented in an objective and operational dimension, which can be used as "indicators" of SL in a student. It is considered that such indicators may be diagnostic tools for SL, for both teachers and researchers, the latter being the case of this article.

In view of this, the analytical core of this article - focused on understanding the dimensions of SL praxis - was developed in the light of clarifications and intellection of the authors mentioned in this section. We seek, mainly, to establish new insights into the SL occurred in the course of changing the school environment through the school museum project (Barcellos, 2013) adopted by the participating teacher. In the

\footnotetext{
7 The Programme for International Student Assessment (PISA) is an initiative of comparative evaluation, applied for students around 15 years-old, the age when mandatory basic education ends in most countries (INEP, 2015).

${ }^{8}$ Here understood as synonym for SL.
} 
following theorizations we will present, which are focused on the dimension of the space/environment where the experiences and events occurred, we wish to differentiate "Space" and "Environment" in the school context. We analyze their specific "intentions" and possibilities within a school context in which seeks an educational praxis of SL defined by the conceptual and explanatory constructs of authors, such as Chassot (2003), Sasseron and Carvalho (2011), Freire (2011), and Demo (2010; 2011), consisting of a pedagogical constructivist practice according to Roque Moraes (2003).

\section{Spaces or Environments? Transfigurations}

Teaching science does not mean transmitting a set of previously selected knowledge, it means an effort to scientifically literate individuals and allows them to alphabetize themselves and exercise transforming action over reality. For that to happen, the design of logocentric education and banking education needs to be transformed by a perspective that sees knowledge as a construction, (inter)subjective to each of us, not being a direct result of the teaching action.

Assuming that the space in which learning takes place reveals epistemological conceptions of teachers, and especially, highlights cultural traits of those who occupy it, the space must be resonate with the pedagogical project and the individual it aims to form. In this sense, a science teaching allied to SL, aimed at critical formation of the individual and the relativity of science cannot take place in a sterile environment, marked by the distribution of bodies in a room.

Thus, the educational changes are associated with the modification of the spaces in which classes take place. The traditional classroom, due to the centrality of the teacher who holds the "stage" and the availability of resources, such as desks that refer to an idea of centralizing knowledge for all to see, should be deconstructed. It should give rise to an aesthetically comfortable environment that allows the integration of the people who occupy it, since knowledge, before being something ready, is an argumentative and subjective construct.

Reality must be present in the classroom, but without making education something utilitarian. Chassot (1995, p. 155) pointed out that science teaching must be placed "within a conception that highlights its social role, through social, political, philosophical, historical, economic and (also) religious context". The classroom where the walls close to an alleged "outside world" and that, through the "veneration" of a pure and "fearless" scientific knowledge, cannot be considered a suitable place for the SL defended this manuscript.

To Horn (2004, p. 20), "The environment is a major factor in the development of individuals, being a constitutive part of this process," influencing positively or negatively the development of learning. It is in this environment that we establish relationships that enable knowledge to be built through subjective interactions. In this respect, we must suggest spaces that will allow contact with the realities the student sees, feels, touches, and acts. Such interactions may serve as symbolic models, which are a channel through which the individual interacts with the environment, and that is the physiological activity (Vygotsky, 1987).

You can find a suitable environment to SL when it is facing reality and exists as a facilitator of learning and creations. The most common "non-formal" spaces are museums, centers, clubs, and science observatories. These sites allow their patrons to explore significantly, seeking answers to their interests and curiosities, acting in complementarity to the pedagogical project of the schools (Trilla, 2008).

Due to the poor accessibility to non-formal spaces for schools that are located far from urban centers, or with no resources to access them, we are led to think about alternative school environments to promote SL. This would be the transformation of a school environment in a non-formal education environment, such as 
Educational Museum, which is a poly-themed learning center of cultural creations, subjectivities and SL. In this sense, before being a place of exhibits and collections - which is mainly focused on the visual stimuli through the exhibition - it comprises a learning environment in which students "become curators" (Barcellos, 2013). Thus, the museum's educational function becomes compatible with the school. For Brandão (1996), museums have a role associated with their own origin, because from the beginning they were characterized as spaces for research and teaching.

As Barcellos and Vargas (2015) stated that the organization of a school museum has the aim of familiarizing students with the process of building scientific knowledge, allowing students to interpret and transform the environment in which they are inserted, grounded in scientific knowledge at the same time as they can reflect on the nature of science. Thus, we propose a break with the logocentric education. In this environment, we desire to reach learning through experimenting, exploring and manipulating (i)material objects. We consider that students will become "familiar with the process of creation of knowledge, and understand it is a historical and social place" (Barcellos \& Vargas, 2015, p. 39).

According to Barcellos (2013, p. 27), an Educational Museum consists of "a medium, a tool, to perform SL through an (inter)active, (re)constructive, analytical communicative, emotional, and affective process." Hence, more than a teaching space, an educational museum is a learning environment that can facilitate an investigative approach and interpersonal relationships, providing a bio-psycho-social understanding of the people involved. In this environment proposal, we considered the emotions in the process of teaching and learning. It is noteworthy that education in museums has remarkable attention nowadays; especially concerning the social role of practices carried out in that space and possible reflections they may catalyze (Fronza-Martins, 2012).

Even though many schools already have science laboratories for classes, it should be noted that the process of teaching and learning that could occur in this space does not always include the requirements for SL, since many experiments conducted in these areas merely demonstrative. Therefore, the use of practical activities per $^{9} e^{9}$, still links teaching to concepts of banking education and content-driven education, basing new practices on old epistemological theories, without overcoming the pedagogical common sense.

Since museums in general are institutions dedicated to the conservation of memory, they perform an essential role in the development of cultures and social identities. This is why, according to Falcão (2009), they provide public interactions with researchers who "celebrate" the past, consequently allowing people to reflect on the present and transform realities.

From this perspective we seek, in this study, elaborations on educational aspects of the Educational Museum process. We present the ways in which the implementation of an environment and its educational activities made possible for students to overcome difficulties in content-driven and technicist conceptions of teaching. To understand the "phenomenon" in its nuanced and specific dimensions, we initiated a qualitative research in which the narratives of a teacher are as elements full of meaning and subjectivity.

\section{Methodology_“Narrative Complex: (Macro/Micro) Analysis”}

In this study, we analyzed the pedagogical experimentations developed by a teacher of the public school system of 26 years-old and working for the state for one year. He teaches five groups of the 1st year

\footnotetext{
9 We understand it as a synonym for "experimenting", meaning, experimental activities where we seek to understand a phenomenon by using lab equipment and controlling variables, so that they can be compared, and/or described and analyzed.
} 
Polytechnic School of a public school located in socially vulnerable region of Porto Alegre-RS. We analyzed his project for over a year (2014), and given the methodological procedures of the research, our own investigation became narrative in its nature.

The narrative research focuses on broad issues such as how people teach and learn; how the context and temporality connect with change and learning and how educational institutions become a frame for the lives of those involved. The narrative is central to the understanding of a phenomenon (Clandinin \& Connelly, 2000).

Life is full of narrative fragments that took place in moments of time and space in the form of stories, reflected and understood in terms of narrative units and their discontinuities. In narrative thinking, temporality is central, that is, you need to locate events in time and space in order to think about them (Clandinin \& Connelly, 2000).

In this regard, the actions of a teacher can be seen as narrative symbols that express meanings and clarification of a phenomenon in analysis. In the explored narrative, it was necessary to consider the context, which can be temporal, spatial and/or social. From the understanding of the context(s), it is possible to draw correlations and developments with the presented theoretical framework.

The narrative research uses a phenomenological approach, thus referring the thoughts of Benjamin (1994). For this author, narrative does not mean to "pass on the 'pure aspects in themselves' of something" narrated as a piece of information or a report. "It plunges that thing in the narrator's life to then withdraw it from him" (p. 205). The narrative is, as a result, the communication of what was lived and experienced by the subject himself involved in educational activities. This is on the assumption that experience:

refers to all events occurring within the phenomenal world or perceptual field of the individual; IT refers also to all that affects the experience at the time, be these aspects conscious or unconscious. That is, we can understand the [...] experience as a reference to the lived world, the existential moment of the person, including therein all the experiences that make up such a moment in time. (Dutra, 2002, p. 372)

Ergo, a narrative communicates perceptions of life experiences. In turn, Silva (2014, p. 564) pointed out that is "a way to study how individuals shape their experiences and give previously unknown meaning to their experiences." The narrative research, therefore, involves a subjective dimension, which seeks to the perception of the individual on the experiences through which they are affected. According to Benjamin (1994):

[...] It is an artisanal form of communication. It is not interested in conveying the "pure aspect in itself" of what is being narrated as information or a report. It plunges that thing in the narrator's life to, then, withdraws it from him. This way we imprint the mark of the narrator, such as the hand of the potter in clay pot. (p. 205)

The use of narrative as an instrument of data collection followed the assumption that the professional and personal selves of the teacher are inseparable. According to Barcellos et al. (2015), the knowledge of teachers can come from several different areas of their social lives, especially the family environment, from their academic training, from readings for their professional live, or even from their own experience. That is why we can "extract" different nuances from what is narrated. Thus, when someone narrates experiences it is possible to rethink and rebuild on stories, making thinking rationally and affectively entwine in an indissoluble way (Telles, 2002).

The narratives are made of "reconstitutions" of reality, which is implicitly coated with the author's past experiences. As stated by Cunha (1997), the fact that a person highlights situations, deletes episodes, denies 
steps, remembers features or forgets details has many meanings and these apparent contradictions could be exploited for educational research purposes.

In this perspective, Hanson (1975, p. 127) noted, "Observations and interpretations are inseparable- not only in the sense that they never manifest separately, but in the sense that it is inconceivable to manifest either party without the other". Even if the story involves a descriptive dimension of reality, to start from Hanson's (1975) premise, we see that this is not "faithful" to the object it speaks of, but a recreation by the author. The description of the phenomena experienced is loaded with subjective elements of the subject itself, which would eliminate the objective character that is at the heart of scientific knowledge (Chalmers, 1994). However, Souza (2006) pointed out that the narrative:

[...] is built as an investigation because it links itself to the production of experiential knowledge of adult subjects in development. On the other hand, it is considered development because it assumes that the subjects become aware of themselves and of their experiential learning when living simultaneously the roles of actor and investigator of their own history. (p. 26)

It is noteworthy, too, that education is a process that involves subjectivities, and in view this feature, the action of observation and analysis of the facts in an objective way do not make possible for an understanding of the complexity of the phenomena studied. According to Chizzotti (2003, p. 17), "Oral testimony of those present at events, their perceptions and analysis, can clarify many oversights and indicate unexplored facts of the problem." Therefore, the action of reporting the developed practices allows us to communicate the intentions of teachers and their perceptions of the practices developed. It means presenting the subjectivities involved in educational activities.

The narrative offers a (re)constitution of the praxis, in which the "participating teacher" (the subject of this research and an author of this study) reports his experiences. Data collection took place throughout the 2014 school year, during the observation $200 \mathrm{~h}$ of classes and school activities. The 77 students involved were "indirect" subjects of the research, once their actions are considered based on the observation of the authors and the participating teacher's narratives. The verbalization of their experiences shows epistemological concepts that remain implicit in their practices, which allows the clarification of the theoretical and epistemological emplacements. The use of narratives as an approach to research allows scientific investigations to be committed to the (re)construction of formal knowledge and also the qualification of the developed pedagogical practices.

The following is a "narrative analysis of narratives" in which those transcribing verbatim what the participating teacher said, appear in italics in the text. In other words, the "analysis" of this study is a narrative of the authors - built from the observations made in the course of the project. It is, therefore, a microanalysis of the narratives of the participant teacher, an account of his research activities carried out with and by his students, those accounts being considered microanalysis. Therefore, we name the "set" of what will be presented if "Narrative Complex," whose accounts are interlaced with analysis and theoretical considerations.

It is worth adding that the analysis presented consists of the dialogue of clarifications of the authors and teacher with theoretical assumptions, with the intention of responding the questions the study poses. We take the narratives with an analysis per se, that is, the very act of narrating already implies analyzing, as there is a dissociated observation of interpretation (Hanson, 1975). Thus, we weave a warp of microanalysis and microanalyses (theoretical thoughts, diagnoses, findings, and conjectures) constituting the Narrative Complex as a synthetic explanation of the phenomenon. 


\section{Results and Discussion-“Explanatory Undulations: Dialogues of Complexity”}

The "Complex Narrative" of creating an Educational Museum is organized into three waves (see Figure 1): (1) creation and selection of topics and subjects; (2) design of projects and experiments; and (3) explanatory conclusion. Note that the idea of three waves stems from the observation, by the authors, of the participating teacher's practice. In these sequential waves, not marked clearly, there is a continuum of comings and goings and an overlap of movements, i.e., there is a constant dialog of complexity (Morin, 2011). Furthermore, we identify in the narratives their SL competences and their centerlines as previously stated in the theoretical framework.

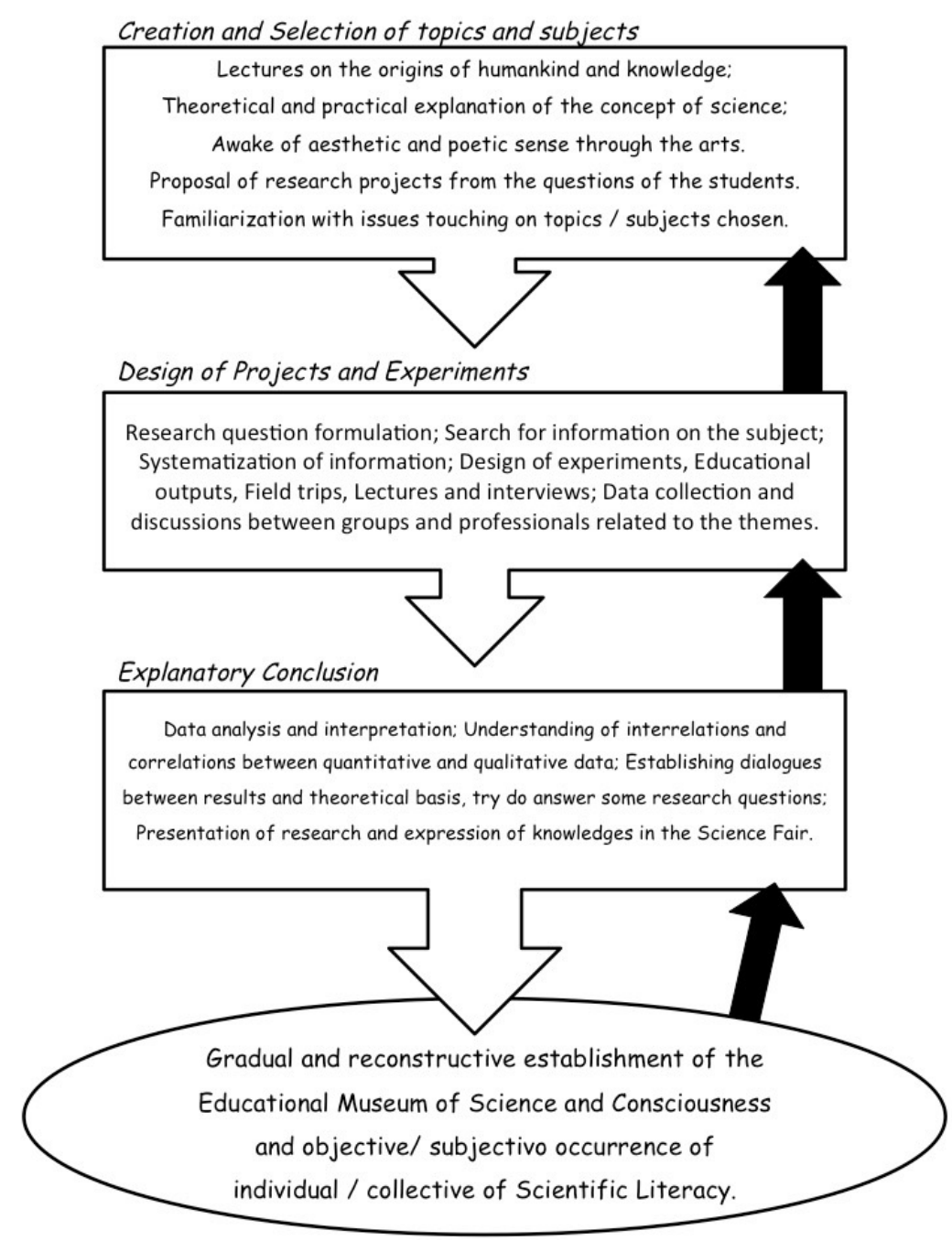

Figure 1: Three waves of the educational museum creation.

The beginning of the Educational Museum development activities included some lectures, in which the teacher selected and presented to the students the history of scientific knowledge. As the narrative shows narrative one (N1):

In these classes, I did not want memorized concepts of our origins as a species and the rise of civilizations or the concurrent construction and complexity of knowledge. I wanted them to see a starting point. I wanted to "start from the beginning." I showed them excerpts from the movie "2001—A Space Odyssey," emphasizing the piece of bone thrown by 
an australopithecine, pointing out how his bipedalism, becomes, in a few seconds, a space station. I wanted to expose a wealth of content. I thought those who did not find the space station interesting, could become curious by the theme "Thus Spoke Zarathustra." It did not matter to me if they would want to study Strauss' music or Nietzsche's book. At that time, I was not worried about the museum, as I already had in mind what they (students) would do, but I did not want to tell them right away, "look at us, we are going to build a museum!" I told them, without details, that there would be a high point; it could be a science fair... What I wanted, really, was to show the immensity of things "we" (humanity) have done, so they would think of all they could eventually realize.

We observe that the teacher sought to avoid incurring in whiggism (Bizzo, 2013). At this stage, we narrate an effort to teach the history of science, presenting it in the complexities and limitations that a particular social and historical moment imposed on researchers and scientists.

In this context, it is necessary to understand that the lectures consisted of one (out of several) strategy of teaching. The teacher adopted an approach, which aimed at students perceiving science as a human, social and historical construct, not radically denying it nor glorifying it as absolute knowledge (Chalmers, 1994). For Giordan and Vecchi (1996), even though lectures can be used as a teaching device, once they do not set out from prior knowledge of students, they can enable us to expose a large amount of information ${ }^{10}$ the teacher may use to problematize the ways in which students understand the reality.

This initial exposure of information cannot be understood as a "dogmatic practice" merely discursive, since information is needed to build knowledge and understanding of reality. Chassot (2003) said, "We cannot build scientific education without having information. I do not mean exclusivity. The center of it all will be the selection of the information to use it for formation" (p. 91).

Therefore, there does not seem to be a discrepancy between the criticism of the dogmatizing perspective of banking education (Freire, 2011) and the use of lectures. Freire (2011c) highlighted that education based on a liberating perspective enables understanding of reality as something in constant movements of (de)construction, in which man is inserted without the existence of a man-world dichotomy. In this respect, knowing the history of science and human knowledge is to understand that science is not the result of history, but part of a process which man is co-participant of this construction.

Moreover, teaching non-dogmatic science enables allows us to realize that scientific knowledge is not cumulative, as emphasized by positivist empiricism. Science is seen not as an absolute truth, but rather as an approximation of the truth. This perception of science as a system of search for truth in an environment of doubts lets us understand it as one of the possible ways of understanding the world, without establishing an axiological hierarchy of knowledge.

After the exposition of a conceptualization of what science and history of science are, students prepare research problems. We should point out that a research problem is a "frill" on the researcher's part, making the students the protagonists in the creation of the question that guided their investigations. However, this assumption did not exempt the teacher from his job, of being with the students, helping them to build their research objectives, as well as acting as a guide in work ethics and challenging students to complexify ${ }^{11}$ their questions and interests.

\footnotetext{
${ }^{10}$ In this perspective, a lecture class would not aim for all students, or even most, to "absorb" and assimilate all that has been exposed, but it would be a moment where a universe is presented, exposing shades and facets from which the students might choose starting points for their "personal" researches.

${ }^{11}$ In the sense of establishing dialogues between areas, meaning bridges between different theoretical fiends, seeking to turn "simple" curiosities in research questions over which they would develop, during the activities, their research projects for the School Museum of Sciences and Consciences.
} 
Allowing students to list their research problems implies recognizing them as historical, powerful subjects with their own conceptual aura (Giordan \& De Vecchi, 1996). Such processes show an ethical relationship between teachers and students, in which the teacher does not place him or herself as a "superior" to the student, but in a position of co-responsibility with learning, recognizing the student as having a culture and a way of seeing the natural world and himself or herself.

Thus, emerged projects with themes here divided into three distinct categories (C): $(\alpha)$ Immediate problems in the student's reality; $(\gamma)$ Problems highlighted by the media; and $(\delta)$ History, culture, and science and their influence on society; as shown in Table 1.

Table 1

Research Projects

Research project theme

Research project theme
(number of students in each group)

\begin{tabular}{|l|l}
\hline 1. Great dictators in history (3) & $\delta$ \\
\hline 2. Military coup and its dictator (1) & $\delta$ \\
\hline
\end{tabular}

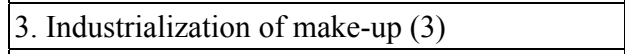

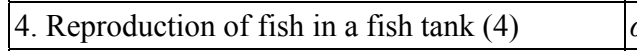

\begin{tabular}{|l|l|}
\hline 5. Research on prevention of AIDS (3) & $\alpha$ \\
\hline 6. Leonardo da
\end{tabular}

\begin{tabular}{|l|l}
\hline 6. Leonardo da Vinci's machines* (4) & $\delta$ \\
\hline 7. History of
\end{tabular}

\begin{tabular}{|l|l|}
\hline 7. History of wine* (4) & $\delta$ \\
\hline 8. &
\end{tabular}

\begin{tabular}{|l|l}
\hline 8. Teach about the Big-Bang* (5) & $\gamma$ \\
\hline 9. Digitalgami
\end{tabular}

9. Digital games: creation and development (3)

10. Paleontology: modeling and excavation of fossils * (4)

\begin{tabular}{|l|l|}
\hline 11. The physics of Surf* (2) & $\alpha$ \\
\hline 12. Prost musc to change the word (5)
\end{tabular}

\begin{tabular}{|l|l|l|}
\hline 12. Protest music to change the world (5) & $\alpha$ & Literature review e rap creation \\
\hline
\end{tabular}

\begin{tabular}{ll}
13. How to save sea turtles $(3)$ \\
\hline 14 Scion
\end{tabular}

\begin{tabular}{|l|l|}
\hline 14. Science and Religion (2) & $\alpha$ \\
\hline 15. Black Holes (4) & \\
\hline
\end{tabular}

\begin{tabular}{|l|l|l}
\hline 15. Black Holes (4) & \\
\hline $16 . \mathrm{LHC}-\mathrm{The}$ Large Hadron Collider*(3) & \\
\hline
\end{tabular}

16. LHC-The Large Hadron Collider* (3)

17. Teaching about the human body (3)

18. Maria da Penha-The Law (2)

19. Comparative analysis of mythologies* (1)

\begin{tabular}{|l|l|}
\hline 20. Endangered sea life (2) & $\gamma$ \\
\hline 21. Photography (2)
\end{tabular}

\begin{tabular}{|l|l|}
\hline 21. Photography (2) & $\alpha$ \\
\hline 22. Ancien Egypt (3)
\end{tabular}

\begin{tabular}{|l|l|}
\hline 22. Ancient Egypt (3) & $\delta$ \\
\hline 23. Homophobia and Feminism (2)
\end{tabular}

\begin{tabular}{|l|l|}
\hline 23. Homophobia and Feminism (2) & $\alpha$ \\
\hline 24. &
\end{tabular}

\begin{tabular}{|l|l|}
\hline 24. Water Treatment (2) & $\alpha$ \\
\hline 25. Cave
\end{tabular}

\begin{tabular}{|l|l|}
\hline 25. Cave dwellers (1) & $\gamma$ \\
\hline 26. & $\alpha$
\end{tabular}

26. Teenage sex and counselling (2)

27. Pollution: a threat to sea life (2)

C Project characterization (type)

$\delta \quad$ Literature review and fabrication of models of concentration camps

$\delta$ Literature review and interview with an author of a book on the subject

$\gamma \quad$ Literature review and experimental tests in the lab

$\alpha$ Experimental activities in the lab, logging and analysis of data

$\alpha$ Literature review and field research with the school community

$\delta$ Literature review and creation of scaled models

$\delta \quad$ Talk and debate with a specialist and experimental activities

Field research with the school community and didactic activities

Workshop and narrative record of activities with a field specialist

Literature review, didactic and experimental activities literature review

$\alpha$ Literature review e atividades experimentais em laboratório

Literature review e rap creation

$\gamma \quad$ Literature review and workshop and interview with an expert

$\alpha$ Literature review and workshop and interview with an expert

$\gamma \quad$ Literature review, visit to the Science Museum and debates on the subject

$\gamma \quad$ Literature review creation of a model in scale

$\alpha \quad$ Creation of models in scale and didactic activities

$\alpha$ Literature review

Literature review interview with an expect

Literature review, visitation to the Oceanographic Museum and creation of a $\gamma$ model in scale

$\alpha \quad$ Literature review and workshop with an expert

$\delta \quad$ Literature review and creation of a model in scale

$\alpha$ Literature review, debates and field research in the school community

$\alpha$ Literature review and creation of a model in scale

Literature review

$\alpha$ Literature review, debates and field research in the school community

\begin{tabular}{|l|l|}
$\gamma$ & $\begin{array}{l}\text { Literature review, visitation to the Oceanographic Museum and creation of a } \\
\text { model in scale }\end{array}$
\end{tabular}

Source: The authors (2016).

In category $\alpha$, problems of the student's immediate reality, we can define it as an effort on the student's part to understand the social and natural reality that surrounds them. When we are familiar with the origin of the researched themes, meaning, when we rescue drafts from the projects, some connection with the student's 
own life stories becomes explicit. There is no dichotomy between the learning subject and the social subject. The students, young people immersed in a complex social web, go to school carrying their problems, their affectations, their passions and the dilemmas they face on a daily basis. Working on that investigative perspective means overcoming the existing dichotomy between the student in school and that student in society.

In category $\gamma$, problems highlighted by the media, the students took the work they had already done as a starting point. It is noteworthy that the emphasis in these projects can reveal the desire to speak of an environmental issue — or of ethics in contemporary scientific research, as was evidenced by the monitoring of how the projects were conducted. This way, the efforts spent by a group of students in their research were recorded in $\mathrm{N} 2$ :

In the project [16] about CERN's "The Large Hadron Collider," the four students in the group, when reviewing the literature and, as a result, the design and construction models of the project, said that their goal was to make science accessible. They told me that people are unaware of the scientific part of the project, but cling to the myths surrounding it. They wanted to show that, although abstract, the experiment was not supernatural. They created a model with an air compressor, hoses and small metal balls representing the particles. A museum piece. They first tried to do it with water, but it did not work. They explained the experiment to their colleagues, but realized they were explaining it to themselves as well.

We see that there is a "basic understanding of terms, knowledge and fundamental scientific concepts," the first centerline of the SL (Sasseron \& Carvalho, 2011, p. 76), when observing the commitment showed by the students in striving to teach science to their classmates (see Figure 2).
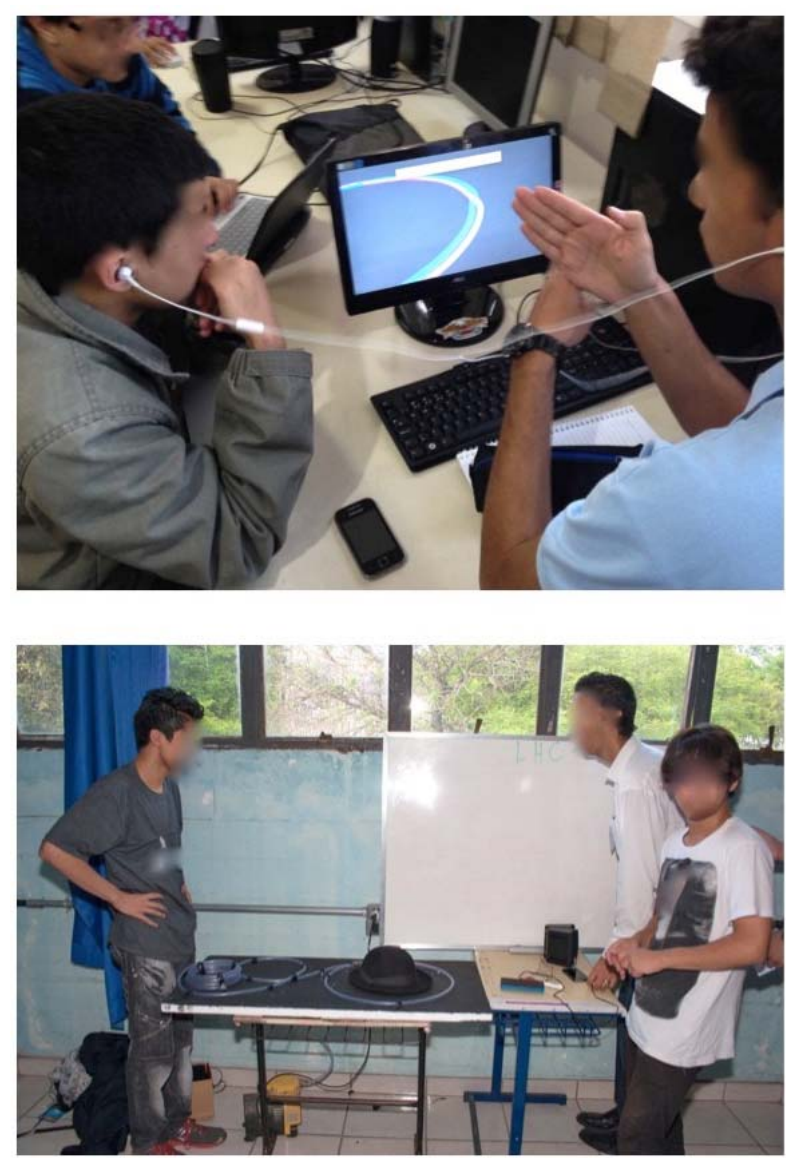

Figure 2. Literature review (above) and presentation of the model at the Educational Museum. Source: The authors (2016). 
The project [08] presented a particular didactic process, as is shown in N3:

\begin{abstract}
A group of five students demonstrated a division when the themes were proposed. Two students aimed to study the formation of the solar system, and two others were interested in studying "children's learning", because they claimed about pursuing a career in teaching. I suggested investigating the conceptions elementary school students have about the origins of the universe. They interviewed six years old students, recording them, and after two weeks, received us at the science classroom, after turned to an Educational Museum, to watch a video. It was very exciting to see the wonder of those children, watching themselves. After each of them spoke, they watched an explanation, by the group, about the origins of the universe. Not as an "explanation of how it really was" but as a conception of the "older" classmates on the subject. In their explanation, the group showed - from the Big-Bang to the formation of the solar system - the evolution of the Cosmos, using a "scenario" and models made from painted expanded polystyrene and paperboard. It was undoubtedly the most striking of experiences, mainly because we saw the integration of students of different ages.
\end{abstract}

With this project, there was an effort to scientifically literate the participating children, allowing them to perceive their own understandings and those of their classmates. The students from the group that taught children made a striking remark of how they learned when teaching, and that the children from the initial grades did not learn the "correct view" of a phenomenon, instead they learned that the same phenomenon could be seen in several different ways. Their view agrees with Hume's ${ }^{12}$ conception, that no person perceives/notices things exactly like the other. Every idea of something is a singularity. In the third category, are the research topics related to history, culture, and science and their influence on society. It is worth pointing out that the projects developed in this category overcame an existing opposition between human and natural sciences, once this category also held projects on social and political processes. The preparation of the project [06] is described in N4:

The motivation of those students to build the research project arose through the existing association in fiction literature between Leonardo da Vinci and the Illuminati. They had many questions about what was behind that aura of mystery and conspiracy theories. [...] The students read the book about Leonardo da Vinci, and wanted to know what was true and what fiction was. In the history of science classes, they were motivated to seek bibliography to learn more about Leonardo as a scientist, not just as an artist of the Renaissance. They learned that he elaborated designs of military equipment, drawings of human anatomy and a helicopter model. They were surprised when I told them the device had never flown, but the principle of it had been correct. They wanted to understand the reason for this apparent inconsistency.

In N4, we observe that the project includes an activity involving an "understanding of the relationship between science, technology, society, and the environment," one of the three centerlines of SL (Sasseron \& Carvalho, 2011, p. 76). It evokes technology content on prototypes designed from the explanation of natural phenomena - properties of matter, which were essential for the students to understand the reasons for the characteristics of the machine, since they chose to build a replica of the "flying machine." From the model developed, students explained why, even not having flown (see Figure 3), Leonardo's projects were consistent with laws of nature that had not even been elucidated in the time he lived. One student said he thought it very unfair that Leonardo did not "live long enough" to see his projects aided by a technology that could in fact make them work (N4).

${ }^{12}$ David Hume (1711-1776), Scottish philosopher, essayist, economist, and historian. 

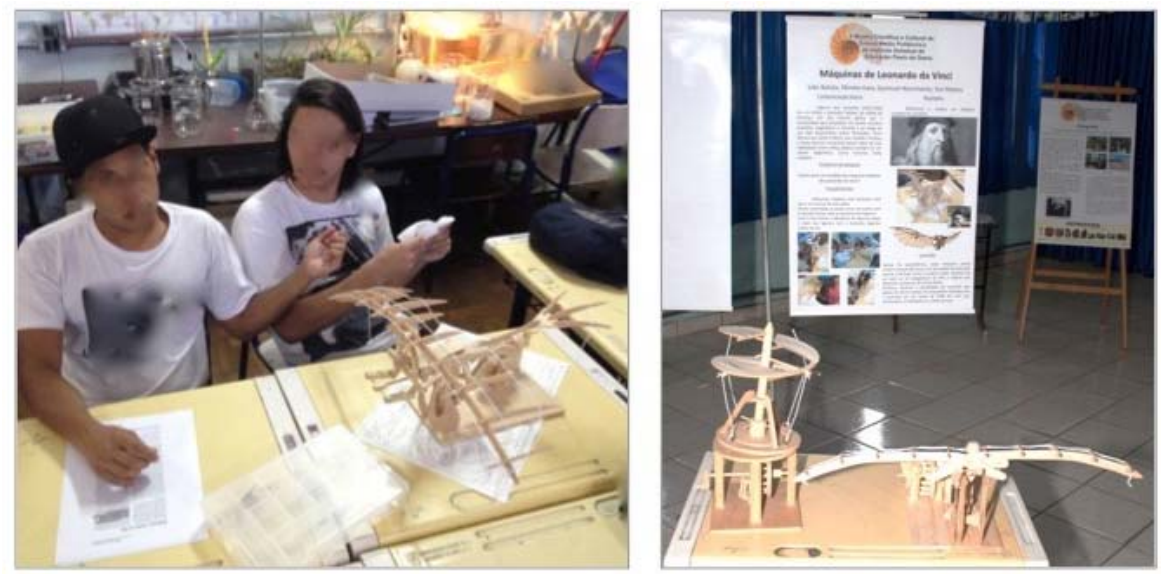

Figure 3. Model creation (E) and presentation of the models (D). Source: The authors (2016).

In N5, we observed the development of a project [11]:

[...] In which two students, motivated by the interest in this sport, conducted studies on physical phenomena that occur in surfing. They developed a surfing mini-board in Styrofoam and a weight simulating the surfer. They tested the model in a rectangular basin, made ripples, and sought to find equilibrium points. The students also made other surfboard models, with other shapes and sizes, testing them during classes. They measured, times and took notes, calling me occasionally to show their progress or ask help with a problem.

From N5, it is possible to identify SL second competence: "Evaluating and planning scientific experiments" (OECD, 2013, p 5), as the students did in their scientific research to "identify their research questions and if proper procedures were used, proposing ways to possibly address such issues" (OECD, 2013, p. 5). In the project [19], according to N6:

A student conducted comparative studies on mythologies and cultures, motivated by her religious beliefs, she developed a survey drawing parallels, questionings and weaving comparisons between the "myths" stemmed from three different sources: Greek, some African religions, and Catholicism, also addressing aspects about the religious syncretism. She interviewed a friend who was also her "pai-de-santo" (African-Brazilian religion "priest") and developed conjectures and reflections on the explanations of the religious. She brought up a subject that was treated by some teachers and colleagues as something inappropriate or improper for the school environment, defying prejudice and bringing to light a subject imposed by law to be taught in all Brazilian schools (Brazilian Federal Law Number 10,639). It was an interesting experience to see that specific knowledge added to their list of school knowledge by a student quest.

This student could "interpret and evaluate data and evidence scientifically and assess whether the conclusions are justified," the third competence according to the $\operatorname{OECD}(2013$, p. 5).

The student also achieved these results through the analysis of the obtained qualitative data, weaving reflections and conclusions based on the content she had previously studied, supporting her hypothesis that "religions and mythologies had traits in common, and this was not a random remark. I was very gratified to see the girl was able to establish relationships, escaping from a superficial observation" (N6).

We could also see SL as an "instrument for political empowerment, allowing the students to build a critical analysis of the reality in which they are inserted and the possibilities of transforming of that environment through a creative and expressive conduit" (Lorenzon et al., 2015b, p. 43). In the project on "Paleontology" [10], students developed fossil models and made reproductions of paleontological excavations in the laboratory, according to the N7: 
One of the three students said he liked to study about dinosaurs. They were shy. They were not very comfortable with the idea of choosing subjects at will, by themselves. I suggested we made modeled fossils, had "excavations" and studies on "real" fossils. I took books to school and some fossils of trilobites and ammonites, per-mineralized bone fragments of Triassic reptiles, plant fossils, fish and fossil models in plaster and resin. In the first few classes I let them touch the fossils, examine, seek to identify the specimens, research on when they had lived, what they ate, when and why they were extinct. I taught the students about a type of fossilization (by counter-mold) making a modeling that "recapitulated" fossilization itself. The students painted models, and they made even more. They had excavations in a box in which I had put the resin replicas. In each layer a time and a fossil, showing that from the depth of deposition, we can infer the age of the creature. After a few weeks, they had developed some knowledge so that they themselves prepared an excavation for other classmates to do.

It is clear, in both cases, N6 and N7, with History of Science or Political and Social Facts, that students have developed an "understanding of the nature of Science and Ethical and Political factors that surround the practice", the second centerline for SL (Sasseron \& Carvalho, 2011, p. 76). In addition, the students' role in defining the theme of their own research, according to Demo (2011), shows the student is a historical subject inserted in an environment and in a complex social network that must be understood and comprehended. The students, by asking themselves about issues that involve and affect them daily, conduct an ethical and existential "exercise" that allows them to stand as actively participating parts of and in the historical process.

Later, with the definition of a research problem and the delimitation of the theme of study, the students began a stage of understanding and explanation, guided by their teacher. At this stage, we begin a capture exercise in building a context in which knowledge is inserted. We also highlight here, that, at this time, there is a demystification of knowledge as something finished, a ready and changeless truth. Students are not restricted to a bibliographical and theoretical search, but are encouraged to develop scientific models, interviews, guided tours and consultation with experts in their areas of investigation.

Even if knowledge is an abstraction of reality, we set out from the assumption that it emerges from the tangible. The abstraction would be the result of the students' empirical perceptions and experiences. Therefore, start out from Hume's assumption (1985) that abstractions are perceptions "made more complex"13, coming from experimentations and observations about the phenomena studied.

Similarly, students involved in the project "Studies on Fossils" built fossil replicas (see Figure 4), making use of materials such as liquid silicone and plaster (Barcellos, 2013). For Demo (2011), scientific modeling is a process of creation and invention of materials that allows us to come close to a certain reality, simplifying it and making it understandable.

Therefore, the construction of a model allows us to come close to that reality and make observations and experiments without modifying it. This is, consequently, a strategy to overcome the purely/directly conceptual teaching. In this perspective, the construction of a concept comes after building the model, breaking the theory-practice/theory-reality dichotomy. It is a movement to understand reality, without a "gangly" and non-significant binding of knowledge-reality, because a non-significant learning can be harmful to the critical thinking of the subject, since it can become a catalyst for the spread of mental alienation (Vygotsky, 1987).

Even in the humanities, building models is a present aspect. For example, studies and model constructions simulating society in ancient Egypt or building scale models of concentration camps. It emphasizes, again, that the construction of these models is preceded by an effort to understand the reality to which they belonged, not

${ }^{13}$ In the sense of having been made complex, according to Edgar Morin's (2011) conception of complexity. 
being a simplification of reality or a reproduction thereof, but rather a reproduction that keeps similarities with the real object of study.
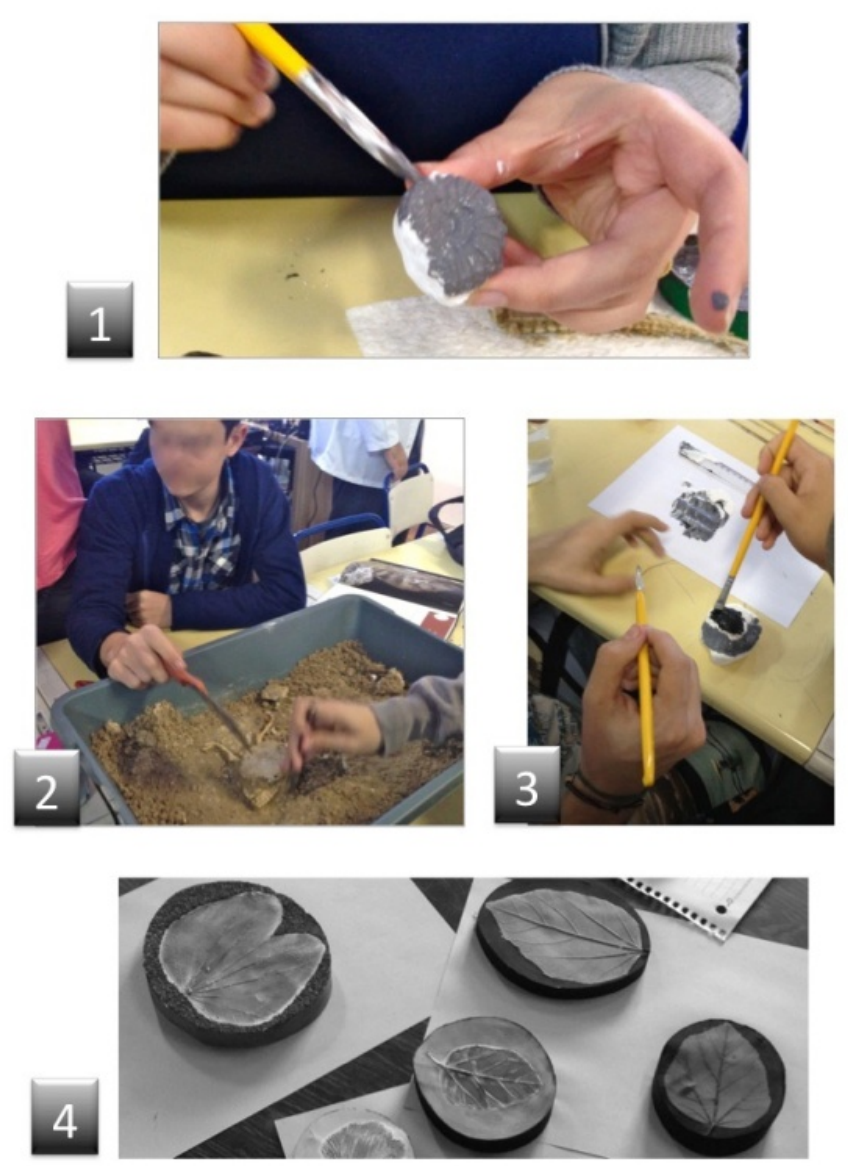

Figure 4. Ammonite fossil model painting (1); Excavation (2); Modeling a trilobite fossil (3); Fossil models of angiosperm leaves (4). Source: Authors (2016).

It is worth noting that in the same way empirical models were built by students, there was also survey data. For example, to understand "the perceptions of colleagues on homophobia in school" [23] or "the care taken by teenagers regarding sexually transmitted diseases" [05], the groups created collection instruments and analyzed data. The empirical survey information shows the significance of bibliographical studies, but also a new understanding of the surrounding reality. In this information resides the concern with understanding the world in which the student is inserted and the subsequent actions to transform it.

The lectures and discussions with experts on specific topics consist of another strategy employed for SL in the creation of student projects and the implementation of the SMSC. The students in the project [07] participated, in the school, of a lecture on the "History of Wine"-research topic of a particular group, in which the speaker was a teacher and French anthropologist, with a Master's degree from Sorbonne ${ }^{14}$. In this exhibition, he spoke with students about the theme, discussing topics such as the history of wine, the climatic conditions of the producing regions of grape and chemical processes involved in the production. The teacher of the classes took the opportunity to review certain aspects worked in class at the beginning of the project, including

\footnotetext{
${ }^{14}$ Université Paris-Sorbonne (France).
} 
biological evolution by artificial selection of species and the work of humans for increased productivity. The students asked questions to the speaker, which helped them in their research project.

The same happened in other projects, such as in the project [13] where students obtained "their records of an interview via teleconference with an oceanologist who was the founder of a protection project for marine turtles" as research data. In the project [13], where students promoted a discussion with a lutheran pastor, graduated in Theology and Biology, master in Philosophy and also a historian, looking for reflections on the interface of Christianity with science. Another example is a [21] project in which the students took a photography course with a professional photographer who came to the school three times to teach the classes and [09]. The students also had the same type of activity [21] with a video game designer. These activities are in line with the assertions of Lorenzon and coauthors, when state, "the formation of citizenship and political empowerment $[\ldots]$ would occur at the time when science education contemplated introducing students to the multiple dimensions of reality and science, including the nature of scientific knowledge and the history of science" (2015b, p. 40).

Reality is presented in a complex way (Morin, 2011), considering the division of knowledge in grades or areas is a human solution. When we make a movement to understand reality, it is possible to realize the limitations of school knowledge Cartesian fragmentation. A talk with an expert or someone who has thorough knowledge of a particular subject, allows an observation of the complexity of what is being studied, once the school, when making the content more didactic, often sterilizes and simplifies a set of isolated facts (Morin, 2011). Similarly, the conversation allows contact with someone involved in the process of knowledge deconstruction, creation, and expression of ideas.

The students in these research groups had the idea for a pedagogical field trip [13], [20], and [27]. They visited a Museum of Science and Technology (City of Porto Alegre-Rio Grande do Sul state) with the students of the project [15] and an Oceanographic Museum (City of Rio Grande-Rio Grande do Sul state) with almost all of students in the five classes taught by the participating teacher. Conducting this activity gave the group greater contact with scientific research and communication. This placed the students in an environment of formal reconstruction of knowledge, where research takes place as a scientific principle (Demo, 2011). These spaces act in complementarity to the educational process that happens inside the school (Trilla, 2008).

After elaborating a corpus of information and data, which formed the substrate of the students' research projects, i.e., the theoretical background and the empirical projects, they carried out analysis and synthesis, in which the students could express their thoughts and emotions about what they were investigating. This way, the third centerline of SL was set up, the "understanding of the relationship between science, technology, society, and the environment" (Sasseron \& Carvalho, 2001, p. 76).

In short, the "II Cultural and Scientific Fair of the Polytechnic High School," held in the school auditorium, served as a means of expression, assimilation and balance (Moraes, 2003) of the learning acquired during their research projects. The presentation was the moment students exposed the projects they developed, but it also represented also the new questions and emerging concerns regarding their objects or topics of study. We highlight here the observation a student made during the fair, who stated that, just as his classmates, he was presenting the results of his research for the "pleasure" the process gave him and the joy of telling what he knew, not out of concern with the school grades he would get for that.

In this perspective, the student was "more than prepared to conduct tests and assessments" (Lorenzon et al., 2015b, p. 43), since, along with other colleagues, he became empowered by knowledge to intervene in the 
world he lives in, with actions permeated by ethical, political and aesthetic values. We would add that a scientifically literate person makes decisions involving questions relating to welfare (Lorenzon et al., 2015), Sustainable Development and Human Rights.

\section{Conclusion: "Synthesis and Considerations"}

In seeking to shed light on the practice of SL, we should consider the transfigurations explained in "Complex Narrative" allow us to say the experiences developed in the phenomenon studied permitted the formation of an environment favorable to SL. According to Barcellos et al. (2015), "A practice of school innovation begins [...] by an immaterial procedure: change the ways of thinking about education/teaching and actually think critically about what someone did, what one does and desires to do" (p. 28). With that in mind, the various changes in teaching and learning processes were causers/caused by the innovations that endorsed the complexity of a "space" in an "environment". The void barrenness of the space to the multifaceted sepsis of an environment. Moreover, according to Barcellos et al. (2015):

Pedagogical innovations [...] thus constitute a complex action, since they involve tensing [...] organizational invariants of the school and pedagogical common sense. Modifying the school education system requires more than normative impositions, but a commitment [...] to modify the practices that concern the sphere of knowledge, but also the emotional sphere. (p. 29)

The experiences were observed in the course of the experiment presented the students several possibilities of actions that gave rise to extensive insights into their chosen themes. Avoiding logocentrism and the traditional way of memorizing contents gave the learning process a well-being perception. This provided ability in the experimental and theoretical movements for new understandings. We can state that such innovation was instrumental in the accession of students to projects that would make up the Educational Museum, once "the proposed construction of an "Educational Museum" makes it possible to break with the homogeneous distribution of students in space, with unidirectional teaching, and the asymmetric relationship between faculty and students, and especially with the measured time" (Barcellos et al., 2015, p. 23).

We should point out there was no gap between the content and the practices, but an attempt to change the direction in which learning occurs. Instead of submitting to thematic lectures that would be anchored in reality a posteriori, they were offered reality as a starting point. In an effort to understand the incomprehension of reality, contents emerged into tools to help answer questions about the surrounding world and no longer as the central object of teaching. Thus, it was developed a "living space for interpersonal relationships, for developing of responsive ethics, but mainly for the appreciation of the specific learning time of each person" (Barcellos et al., 2015, p. 23). That space has become, as time went on, an environment of political empowerment and consequently of SL-since, pending the microanalysis of narratives, one may "detect" that the activities related to the Educational Museum contemplated the three centerlines of SL (Sasseron \& Carvalho, 2001) and the three competences of SL (OECD, 2013). A school space-physically, the room where Biology and Science classes took place-was transformed into an environment for/with/by students to (re)signify their knowledge in a contramundi movement, transgressing logocentrism and "organizational invariants of school and pedagogical common sense" (Barcellos et al., 2015, p. 29) through actions that turn museum artifacts (models) into "mindfacts" 15 .

15 Term used by Chassot in the book From Discipline to Indiscipline (2016). 
In addition, it promoted a self-critical reflection, as the assessment was collective, considering that, when students exposed their understanding of their studies, they were able to, by themselves, assess their level of knowledge and dialogue with classmates.

It is also relevant to comment on three specific situations - given the qualitative nature of the study, which, however, denote some non-specific traits of the adopted practice: (1) Students were free to choose to participate or not. The teacher always "invited" them for the activities, however, those who did not want to do research, had the option to do other activities during the classes. The only "compulsory" factor was attendance, for legal reasons; (2) A student made his literature review and experimental research, but at the time of presenting at the scientific fair, he left the fair. Such an act was interpreted by the teacher as "his limit" and was not judged as "insufficient", but simply as the production of that particular student, within what he wanted and succeeded to achieve; and (3) Four groups participating in the fair and the Educational Museum, not listed in this article, were students that were not in the classes of participating teacher that year. They developed their projects in an "autonomous" fashion and asked to be involved in the movement that was happening at school. Such findings are not shown in the data analysis, because they carry a conclusive meaning and enunciation about an important trait of the narrated phenomenon: the protagonist and active role of the students. Moreover, the essence of the project involved a modification of a way of learning, breaking with the logocentric logic "contents $\rightarrow$ reality" and moving on to a complex model (Morin, 2011), more open and diffuse, in which we sought to understand reality and learn through a non-fragmented view, as shown in Figure 5.

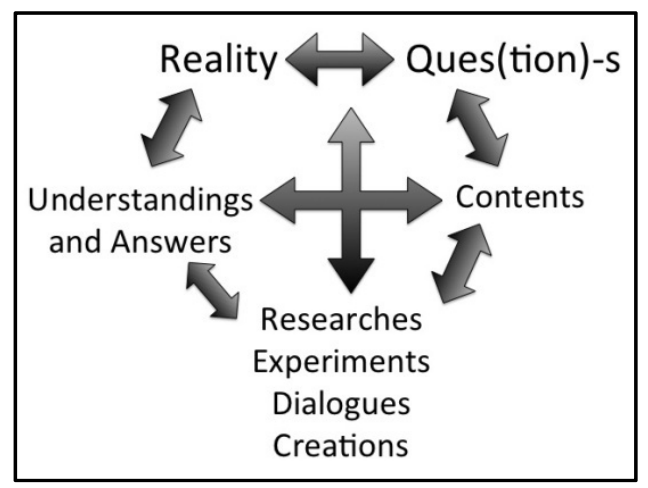

Figure 5. Learning through anon-fragmented view diagram.

By way of deepening this final section, we used excerpts of narratives in which the participant teacher prepared concluding observations. From the very beginning of the project, it was possible to see the teacher had no specific "finality" in mind, due to his constant affirmation that "products do not interest me more than processes" [N8]. We observed that, despite targeting the implementation of the SMSC, he did not want a museum per se, but to achieve the steps that lead to one, in line to Machado's words: “[...] walker, there is no path, you make it as you walk it" (1999, p. 113). Ergo, the museum was not the central objective, what was central was the learning necessary to build a museum. The "Explanatory Culmination" consisted of all processes converging to the "Scientific and Cultural Exhibition," an event in which the students could exhibit their (i)material constructs and realize that they could, in addition to being the protagonists in the teaching/learning, they could also leave marks in their school. Building a memory, a story, in which they were the actors. 
The implementation of the "Museum of Science Sciences and Consciousness" supplanted material questions and emerged unpretentiously. It consisted of a warp yarn with threads of spontaneity, since the students "unintentionally" turned the school in a museum. The school space transformed into a museum without respecting walls and gates, because many worlds came in and out of school. In addition, moves were made possible for (in/de/re/trans) formations, in view of the teacher's and the students' transgressions as far as the logocentric canon go.

The teacher also proved to be unconcerned with formal assessments, considering that even though "evaluators" had been invited to the show, they were invited to talk to students and leave written testimony with their considerations on the research. There was no intention to establish judgments or hierarchies, but dialogues of (cons)sciences and new creative possibilities, the space of the "Scientific and Cultural Fair" became an ancient Agora environment.

Although there were varieties in the "quality" of the researches, the professor found that student who need to and can be self-evaluated, will be able to see where and how they can improve. It is not about "applauding anything"; it about empowering the student with "self-criticism." "My advisor in my masters respected the stage where it was. She left to see by myself what I needed to change and improve, with time and patience" [N8]. In other words, one can only understand oneself; reality is experienced as a "diving bell." The world seen is a unique mental construct. Understanding oneself is essential to understand the world, which, in turn, is never external.

In the students' posters and texts, where they explained their research, the teacher made a few spelling corrections and revisions of a merely formative, but not essential, order as the teacher said, "I made suggestions, helped in what they were asking, and when they asked if the work was good, I returned the question. Many have sought me after the fair telling me what they were going to do to 'improve' their projects. My concern was not pointing out errors, but in giving wings and freedom to their thinking" [N8].

The students who developed the research on the Big Bang with colleagues from the earlier grades told the teacher "the main learning point for them was that no one understands the world the same way. Even when it is an identical fact. Therefore, they could not understand the disrespect to other people's points of view" [N8]. Thus, it can be said that the actions of the students seeking a goal led to other ways of seeing and thinking about the other, and other thoughts.

From students who choose to study sea turtles, mollusks and fossils of starfish, sea, to the students who sought to understand the stars "from the sky," all of them used science to constitute new consciousness, making - in this case - a museum. From the beginning of the project until its closure at the end of the school year, its original title was "Science Museum." However, the participating teacher noted, after the experience, that the most valuable part of the museum (which was disassembled and converted back into a common classroom, in less than one year) were the consciousness of the students who participated. Therefore, we may conjecture that students become aware of the space they inhabit, fomenting scientific thinking and creativity. The school space became an environment of freedom and welfare, while provided an opportunity to SL trough through students' empowerment.

\section{References}

Ausubel, D. (1963). The psychology of meaningful verbal learning. New York: Grune \& Stratton. Barcellos, G. B. (2013). Educational museums manual. Porto Alegre: Edipucrs. 
Barcellos, G. B., Assumpção, R. W. C., Kuchenbecker, C. B., \& Vargas, N. S. (2016). Didactic innovation in science teaching: A qualitative study on the framing of an educational museum in a Brazilian Public State High School. US-China Education Review B, 6(3), 173-185.

Barcellos, G. B., Lorenzon, M., Silva, J. S., \& Biembengut, M. S. (2015). Interfaces entre docência e epistemologia: condições para pensar práticas de inovação curricular (Interfaces between teaching and epistemology: Conditions for thinking curriculum innovation practices). Caderno Pedagógico, 12, 18-30. Lageado: Lajeado Online.

Barcellos, G. B., \& Vargas, N. S. (2015). School museum: A locus for scientific literacy. Educação em Revista, 113, 38-40.

Becker, F. (1992). O que é construtivismo? (What is constructivism ?) Revista de Educação, 21, 7-15. Brasília: AEC.

Benjamin, W. (1994). The narrator: Considerations on the work of Nikolai Leskov. In Magic and technology, art and politics: Essays on literature and history of culture (p. 7). São Paulo: Brasiliense.

Bizzo, Nélio. (2013). History of science and science education: Tools for practical and educational research. In A. V. Amorin (Org.), Science education: Points and counterpoints (pp. 13-59). São Paulo: Summus.

Brandão, J. M. (1996) Cultural action and education in museums. Cadernos de Museologia, 5, 58-66.

Carvalho, A., Cachapuz, A., \& Perez, D. (orgs). (2005). The necessary renewal of science education. São Paulo: Cortez.

Chalmers, A. F. (1994). The manufacture of science. São Paulo: Fundação Editora da UNESP.

Chassot, A. (1995). To whom is useful teaching? Alternativas para um ensino (de Química) mais crítico. Canoas: Ulbra.

Chassot, A. (2003). Scientific literacy: Issues and challenges for education. Ijui: Unijuí.

Chassot, A. (2016). Disciplines to indiscipline. São Leopoldo: Editora Unisinos. (no prelo).

Chizotti, A. (2003). Research in human and social sciences. São Paulo: Cortez.

Clandinin, J., \& Connelly, M. (2000). Narrative inquiry: Experience and story in qualitative research. San Francisco: Jossey Bass Publishers.

Coll, C., Pozo, J. I., \& Sarabia, B. (2000). The contents of the reform: Teaching learning concepts, procedures, and actions. Porto Alegre: Artmed.

Cunha, M. I. (1997). Tell me now!: Narratives as pedagogical alternatives in research and teaching. Revista da Faculdade de Educação, 23(1-2), 185-195.

Demo, P. (2006). Research: Scientific and educational principle. São Paulo: Cortez.

Demo, P. (2010). Education and scientific literacy. São Paulo: Papirus.

Demo, P. (2011). Education through research (p. 9). São Paulo: Autores Associados.

Derrida, J. (1976). "Linguistics and grammatology" of grammatology. Baltimore: Johns Hopkins University Press.

Desvallées, A., \& Mairesse, F. (2013). Museology key-concepts. São Paulo: Secretaria de Estado da Cultura.

Dutra, E. (2002). The narrative as a phenomenological research technique. Estudos de Psicologia (UFRN), 7(2), 371-378. Natal/RN.

Falcão, A. (2009). Museum as a place of memory. In V. A. Arantes (Ed.), School museum: Formal and non formal education (pp. 5-21). Salto para o futuro. Escola, T.V.: Ministério da Educação.

Feyerabend, P. (2011). Against method. São Paulo: Unesp.

Freire, P. (2011a). Pedagogy of autonomy: Knowledge necessary for educational practice. São Paulo: Paz e Terra.

Freire, P. (2011b). Pedagogy of hope: A reunion with the pedagogy of the oppressed. São Paulo: Paz e Terra.

Freire, P. (2011c). Pedagogy of the oppressed. São Paulo: Paz e Terra.

Fronza-Martins, A. S. (2009). The magic of seduction: The importance of non-formal educational activities in art museums. Campinas: [s.n.].

Giordan, A., \& De Vecchi, G. (1996). The origins of knowledge: The conceptions of learners to scientific concepts. Porto Alegre: Artes Médicas.

Hanson, N. R. (1975). Observation and interpretation. In S. Morgenbesser (Org.), Filosofia da Ciência (pp.127-138). São Paulo: Cultrix.

Harres, J. B. S., Rocha, L. B., \& Henz, T. (2001). What do the teachers think about what they think students: Research in different stages of formation in the case of views on the shape of the Earth. Revista Brasileira de Pesquisa em Educação em Ciências, São Paulo-SP, 1(2), 40-50.

Harres, J. B. S. (2003). Investigating professional practical problems: A strategy for the evolution of knowledge of future teachers. Revista Educação, 26, 53-68.

Harres, J. B. S., Pizzato, M. C., Sebastiany, A. P., Cenci, D., Eidelwein, G., Diehl, I. F., \& Mors, M. (2012). The ideas of students in initial training research science teachers. Revista Ciência \& Educação (Bauru), 18, 55-68. 
Horn, M. G. S. (2004). Flavors, colors, sounds, smells: The organization of spaces in early childhood education. Porto Alegre: Artmed.

Hume, D. (1985). Research on the human understanding. Lisboa: Setenta.

INEP. Anisio Teixeira National Institute of Educational Research. Retrieved January 19, 2016, from http://portal.inep.gov.br/ pisa-programa-internacional-de-avaliacao-de-alunos, consultadoem

Kuhn, T. (2005). The structure of scientific revolutions. São Paulo: Perspectiva.

Lorenzon, M., Barcellos, G. B., \& Silva, J. S. (2015a). Scientific literacy and liberating pedagogy of Paulo Freire: Possible linkages. Revista Signos, 1, 71-85.

Lorenzon, M., Barcellos, G. B., \& Silva, J. S. (2015b). Thinking curriculum in science education: Teaching for citizenship and political empowerment. Revista Areté, 8, 36-44.

Machado, A. (1999). Complete poems. Madrid: Espasa Calpe.

Montaigne, M. (1980). Essays. São Paulo: Abril Cultural.

Moraes, R. (2003a). Is it possible to be constructive in science education? In R. Moraes (Org), Construtivismo e ensino de ciências: Reflexões epistemológicas e metodológicas (Vol. 2, pp. 103-129). Porto Alegre: Edipucrs.

Moraes, R. (2003b). Implicit theories. In R. Moraes (Org), Construtivismo e ensino de ciências: Reflexões epistemológicas e metodológicas (Vol. 2, pp. 159-194). Porto Alegre: Edipucrs.

Morin, E. (2004). The well-made head: Rethink the reform, reforScience with consciousness $m$ thought. Rio de Janeiro: Bertrand Brasil.

Morin, E. (2010). Science with consciousness (p. 14). Rio de Janeiro: Bertrand Brasil.

Morin, E. (2011). Introduction to complex thought. Porto Alegre: Sulina.

Organization for Economic Co-operation and Development (OECD). (2013). The PISA 2015 draft science framework. Matriz de Avaliação de Ciências, Paris.

Popper, K. R. (1985). The logic of scientific research. São Paulo: Cultrix.

Ramos, M. G. (2000). Epistemology and science teaching: Understandings and perspectives. In R. Moraes (Org.), Constructivism and teaching of science: Epistemological and methodological reflections (pp. 13-35). Porto Alegre: Edpucrs.

Sasseron, L. H., \& Carvalho, A. M. (2011). Scientific literacy: A review. Investigação em Ensino de Ciências, 16(1), 59-77.

Silva, E. S. P. C. (2014). GESTAR in School and the teaching of mathematics: Life stories and subjectivity in the continuing education of Bahia basic education teacher. In Proceedings of the 1st International Conference on Education and Science Education: Contributions and Perspectives. Salvador: UFBA/UESF.

Souza, E. C. (Org.). (2006). Autobiographies, life story, and training: Research and teaching. Bahia: Eduneb-Edipucrs.

Telles, J. (2002). "It's research, is'nt it? Oh, I do not want!" On academic research and its relation to the practice of language teacher. Revista Linguagem \& Ensino, 5(2), 91-116.

Trilla, J. (2008). The non-formal education. In V. A. Arantes (Ed.), Educação formal e não-formal: Pontos e contrapontos. São Paulo: Summus.

Vygotsky, L. (1987). Social formation of mind. São Paulo: Martins Fontes. 